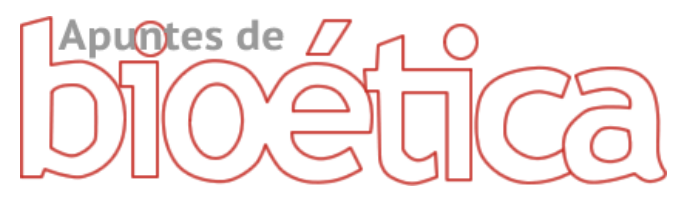

https: //doi.org/10.35383/apuntes.v4i2.700

\title{
¿Hacia dónde vamos? El pensamiento postmoderno y su influencia en los conflictos 0 dilemas bioéticos y biojurídicos
}

\section{Where are we going? Postmodern thought and its influence on bioethical and biojuridic conflicts or dilemmas}

\author{
Aldo Alesandro Santome-Sánchez*, 1, a \\ asantome@pucp.pe \\ https://orcid.org/0000-0002-5208-6489
}

\author{
*Autor corresponsal \\ ${ }^{1}$ Independiente, Lima, Perú \\ a Bachiller en Derecho
}

\section{Fechas importantes}

Recibido: 18/10/2021

Aceptado: 22/12/2021

Publicado online: 23/12/2021

\section{Resumen}

En el presente artículo se presenta un análisis sobre algunas características del pensamiento posmoderno, las cuales han terminado por influir en varios dilemas bioéticos y biojurídicos, como el aborto o la eutanasia, entre otros. Así, se determina que muchas de las posturas actuales, tanto de la doctrina como de la jurisprudencia alrededor de estos temas, han sido fruto de esta corriente de pensamiento, la cual, entre otras cosas, propone la relativización de algunos derechos humanos, como la vida y la libertad.

Palabras clave: Filosofía; Posmodernidad; Bioética; Aborto; Eutanasia.

\begin{abstract}
This article presents an analysis of some characteristics of postmodern thought, which have ended up influencing various bioethical and bio-legal dilemmas, such as abortion or euthanasia, among others. Thus, it is determined that many of the current positions, both in doctrine and in jurisprudence around
\end{abstract}


these issues, have been the result of this current of thought, which, among other things, proposes the relativization of some human rights, such as the life and freedom.

Keywords: Philosophy; Postmodernity; Bioethics; Abortion; Euthanasia.

\section{Introducción}

Usualmente se suele afirmar que la lucha por los derechos humanos es una causa que nos debería comprometer a todos los ciudadanos, sin excepción y con la misma intensidad. De ese modo, todos estaríamos colaborando con la creación de sociedades más justas e iguales, donde todos podamos tener la certeza de que nuestros derechos serán respetados.

Así, en principio, parecería que, independientemente de las discrepancias que podríamos tener en diferentes ámbitos (por ejemplo, en la decisión sobre por quién votar en las elecciones, o en la elección del plan de seguros que más le conviene a uno, o en el apoyo incondicional que uno le tiene a un equipo de fútbol), todos deberíamos coincidir en que lo más relevante para la construcción de una sociedad plena, es asegurar un mínimo de derechos para todos.

Sin embargo, lo que debería ser la tarea común, ha terminado por ser una labor más que compleja, principalmente por las diversas implicancias filosóficas que entran en juego, sobre todo cuando estamos frente a casos complejos, en donde existen más de un derecho humano que entra en colisión con otro.

Así, casos como el aborto o la eutanasia han despertado varios debates alrededor de su naturaleza y sobre las posibles soluciones que tendrían que adoptarse en cada uno de estos casos. De esta forma, un buen sector de la doctrina y la jurisprudencia se han venido inclinando por opciones que, a nuestro criterio, atentan contra la vida, relativizando otros derechos como la libertad de los implicados, incluso si esto trae consecuencias nocivas.

No obstante, en el presente artículo no se procurará hacer un análisis sobre la argumentación usada en dichos debates. Lo que procuraremos es tratar de entender cómo se ha llegado a este escenario. Consideramos que nada nace por casualidad, que las referidas tendencias responden a contextos culturales particulares donde, de alguna forma, han sido gestadas. 
De esa forma, presentaremos un breve repaso sobre algunas de las principales características del pensamiento posmoderno, el cual, como veremos más adelante, ha influido en el desarrollo actual de varios conflictos bioéticos y biojurídicos.

Creemos que solo entendiendo los contextos donde han surgido determinadas posturas, se podrá comprender adecuadamente su complejidad y, al mismo tiempo, se podrá estructurar una mejor crítica hacia estas.

\section{El pensamiento postmoderno contemporáneo}

Tras los hechos cometidos durante la segunda guerra mundial, donde quedó manifestado el desprecio por cierto grupo de personas (como los judíos, personas con discapacidad mental y/o física, gitanos, etc.), la comunidad internacional buscó unificar esfuerzos por construir una sociedad más justa, donde pueda reinar el mutuo reconocimiento de la dignidad entre individuos, lo que se consagró en la Declaración Universal de los Derechos Humanos.

Los horrores acontecidos durante el Holocausto llevaron a una nueva concientización sobre la dignidad humana, con el objetivo de volver a colocar al hombre como un ser valioso en sí mismo, digno de respeto y reconocimiento.

No obstante, pareciera que hoy en día dicho objetivo de la comunidad internacional para devolverle al hombre su estado de ser digno no ha sido arraigado del todo. Al respecto, se puede apreciar cómo hoy en día se habla con mucha naturalidad de varios hechos que, claramente, atentan contra los derechos reconocidos en la Declaración Universal.

Así, la presente investigación gira alrededor de aquellas controversias relacionadas a la bioética y la biojurídica, principalmente, a los casos de la legalización del aborto y la eutanasia, debido a su progresiva legalización.

Como mencionamos, este tipo de problemáticas no han aparecido de manera aleatoria, sino que deben provenir de algún tipo de causa o motivación. Según nuestro criterio, el origen de la naturalización de este tipo de fenómenos es el denominado pensamiento postmoderno.

Según consideramos, esta corriente de pensamiento, si bien ha sabido denunciar varios males problemáticos, como el bienestar ambiental o los derechos de varios colectivos sociales, parece haberse olvidado cómo debería erigirse la defensa de la dignidad humana en los casos que atañe a la bioética y biojurídica. 
Antes de entrar más a detalle, queremos destacar que no es nuestra intención condenar por completo toda propuesta posmoderna (como mencionamos en el párrafo precedente, también ha traído consigo una concientización sobre algunos hechos condenables). No obstante, no por ello deberíamos de prestarle menos atención a aquellas propuestas posmodernas que, por su contenido, atentan contra la integridad de las personas.

Así, para poder entender mejor a qué tipo de influencia negativa nos estamos refiriendo, vamos a presentar algunas de las características del pensamiento posmoderno que, a nuestro criterio, han terminado por influir negativamente en muchos males que vemos hoy en sociedad.

\subsection{Crisis de la razón}

Históricamente, la razón ha sido concebida como una esfera determinante dentro de la concepción del hombre, siendo capaz de orientarle en las principales decisiones de su vida. Así, desde la Grecia antigua, filósofos como Heráclito consideraban a la razón como una inteligencia sustancial a la propia existencia (Reyes, 2013).

Y es que, esa es la noción de razón que ha sido recurrida por varios autores y filósofos por generaciones, entendiéndola, no como una fuerza externa como la gravedad o cualquier otra fuerza ajena al dominio del hombre, sino como una fuerza intelectual que nace precisamente del ser humano para irradiar todo su proceso cognitivo y racional.

Dicha percepción sobre la razón incluso luego fue reforzada por el cristianismo. Sobre el particular, Blanco (2005) sostiene que la razón es considerada como pieza fundamental para la defensa de la ética, la verdad y la fe. De ese modo, la religión cristiana, lejos de repeler el uso de la razón, la constituye como un pilar fundamental para la realización del individuo.

De ese modo, la razón en el cristianismo se erige como un elemento universal que garantiza el libre acceso de todos hacia Dios, independientemente de cuestiones como la clase social, raza o el sexo, reconociendo la plena igualdad entre todos los seres humanos.

De forma especial, queremos traer a colación los aportes de Santo Tomás de Aquino en torno a la razón. El referido autor, identifica a la razón como una capacidad inherente al ser humano que escapa del reino de las cosas palpables, siendo que no interesará si esta capacidad es manifestada en la realidad o no, sino que dicha capacidad será reconocida de 
forma inherente (Lobato, 2000).

Al respecto, consideramos que una concepción de razón como la propuesta por Santo Tomás, resulta esencial para poder conducir distintos problemas bioéticos. Por ejemplo, cuando estamos frente a un caso de una persona con discapacidad severa, la misma que le impide ejercer sus capacidades intelectuales de forma plena.

Bajo la concepción tomista de dignidad, deberíamos defender a la persona de posibles intromisiones a sus derechos individuales, reconociendo que, por más de que no puede ejercer sus capacidades cognitivas en la realidad, ello no quiere decir que no las posea, ya que, por el solo hecho de ser persona, su capacidad racional es inherente a su existencia.

Con la llegada de la modernidad, el concepto de razón fue adoptando una nueva vertiente. Así, por ejemplo, bajo la percepción kantiana, la razón se erige como un medio, mediante el cual, reconocemos a los demás como seres humanos como igualmente dignos. Así, como menciona Sandel (2011), la razón kantiana trae consigo el respeto hacia la autonomía de cada uno y de sus libertades.

Así, según Kant, al reconocer nuestra propia realización a través de la razón, ello implica que, para esperar el mismo reconocimiento de parte del resto de la sociedad, se debe partir del mutuo reconocimiento hacia las libertades de los demás.

No obstante, la modernidad no solo trajo este tipo de concepciones, sino que, adicionalmente, trajo también otras percepciones en torno a la razón. Así, Jiménez (2018) menciona lo siguiente:

Con la filosofía moderna se hace explícita la ruptura entre fe y razón, absolutizando ésta; pero también comenzó entonces el proceso de devaluación de la razón, negándole la posibilidad de conocer lo trascendente. Esta razón, ajena a la fe y a la metafísica, sería la dueña del mundo ("Saber es poder"), imponiendo su dogma. Sólo hay una verdad, la científica experimental; el resto -en realidad las cosas que más nos importan, las del sentido -es fruto de la creencia, opinable y relativa (s/p).

De esta forma, según lo mencionado por la autora, se puede decir que, durante este periodo, se llegó a sobreestimar el rol de la razón. Así, la gran influencia del conocimiento técnico demandó la comprobación fáctica de los principales fenómenos sociales, prescindiendo del conocimiento metafísico. Sobre el particular, lo anterior también fue sostenido por Comte, quien proponía que este tipo de conocimiento era incapaz de poder 
explicar adecuadamente el sentido de los fenómenos, por lo que era necesario pasar a un escenario más "científico o positivo" (De la Vega, 1991). Se podría decir que de esta forma comenzó el reino de lo palpable, de lo exterior por encima de lo interior.

Lo anterior, naturalmente, conllevó a que el hombre sufra una pérdida de la comprensión del mundo que le rodea, conformándose con visión más técnica que reflexiva.

Ello explicaría por qué, si bien en los últimos años se han desarrollado muchos avances científicos, no siempre estos han sido conducidos debidamente para contribuir a la humanidad, por ejemplo, con el caso de la creación de las bombas atómicas. La razón, como era concebida antes, era una herramienta para conducir nuestras acciones, reconociendo a los demás como iguales. Obviando dicha inteligencia guía, se prioriza únicamente lo que se puede hacer, en lugar de lo que se debería hacer.

Sobre el particular, Juan Pablo II (1998), en su encíclica Fides et Ratio, afirmaba:

Sin esta referencia [la de la razón], cada uno queda a merced del arbitrio y su condición de persona acaba por ser valorada con criterios pragmáticos basados esencialmente en el dato experimental, en el convencimiento erróneo de que todo debe ser dominado por la técnica (num. 5).

Según lo desarrollado por Juan Pablo II, ya se pronosticaba los posibles riesgos de priorizar el conocimiento técnico por encima de la razón. Si bien a nivel científico podrían existir considerables avances debido al avance de las ciencias, no había la misma garantía sobre el uso que se le darían a estos, considerando la infravaloración de la razón como parámetro.

Bajo el mismo enfoque opina Fisichella (2011), quien menciona que prescindir del elemento metafísico priva a la humanidad de la conciencia sobre sus propios límites. De esta forma, prescindir de la relevancia de la razón haría que evitemos reflexionar sobre las consecuencias de determinadas acciones, las cuales demarcan un límite al humano, aunque nunca de forma negativa, sino como una guía para que este alcance su máximo grado de bienestar.

Al respecto, nos atrevemos a preguntarnos ¿de qué podrían servir tantos avances técnicos si no se orientan al desarrollo de la persona?

La razón no es la mera capacidad de pensar o de razonar lógicamente, sino que es un tipo de inteligencia que orienta la convivencia. Dejarla de lado, realmente, sería dejar al ser humano bajo un umbral de incertidumbre. 


\subsection{Relativismo moral}

La crisis de la razón ya mencionada trajo como consecuencia que tampoco exista ningún tipo de referencia en lo que respecta a la moral a seguir, haciendo que el bien y el mal se entremezclen sin ningún tipo de diferencia.

No obstante, cabe mencionar que autores como De Lora (2006) mencionan que desde la Grecia antigua se planteaba que no deberían existir ningún tipo de patrones universales, sino que, por el contrario, estos deberían someterse a las costumbres de cada comunidad.

Así, este modo de entender la no universalidad de ciertas normas podría llevar hasta cuestionar la aplicación de la Declaración Universal de los Derechos Humanos, al considerar que los principios mencionados allí son una intromisión a las costumbres de las comunidades que no los reconocen como tales.

En lo personal, consideramos que, si bien debería primar un respeto por algunas tradiciones, por ejemplo, de las comunidades originarias, ello no exime de que existan principios éticos universales y necesarios en donde puedan ser ejercidas libremente.

El relativismo moral, sin embargo, termina negando todo tipo de marco de referencia y, por el contrario, propone un estado de "anarquía moral", donde incluso principios elementales, como el debido respeto a los derechos humanos, podrían ser desconocidos libremente.

Ello conllevaría a una serie de problemáticas, porque entonces la predominancia de ciertos principios no partiría de consensos, sino de la confrontación entre comunidades por ver quién impone sus convenciones culturales en su territorio.

Bajo ese panorama, la convivencia pacífica no tendría ningún tipo de resguardo, quedando al capricho de algunos los parámetros morales vigentes en cada cultura, lo que llevaría al desconocimiento aleatorio de ciertos derechos humanos, dependiendo de los patrones culturales del lugar donde uno se encuentre.

A propósito, queremos volver a destacar que no se trata de desconocer la pluralidad cultural de diversas comunidades, sino que, incluso en su pleno reconocimiento, se adopten ciertas medidas mínimas que promuevan su convivencia paralela, que asegure una pacificación dentro del territorio para beneficio de todos los ciudadanos. 


\subsection{Escepticismo}

Como consecuencia inmediata de las dos características mencionadas previamente, se podría deducir una tercera: la naturalización de la infravaloración, no solo hacia el uso de la razón, sino incluso hacia cualquier otra expresión metafísica, incluso la religiosa.

Sobre el particular, si quisiéramos hacer un repaso histórico en relación a las corrientes escépticas, deberíamos rememorar a la antigua Grecia. Los griegos sostenían que el hombre, para poder llegar a su máxima autorrealización debería basar su existencia en la constante negación de la verdad, en el entendido de que solo así, se podría llegar a las cuestiones más trascendentales sobre la vida, y no conformarse con respuestas parciales que podrían no estar cimentadas en la real complejidad de los distintos fenómenos analizados (Aguirre, 2016).

Posteriormente, esta corriente encontró cierta replica con Hume quien, a diferencia de los griegos, sostenía que debería priorizarse un estado de duda frente a aquellos conocimientos que no pudieran ser corroborados empíricamente. Así, se sostenía que únicamente aquellas contribuciones que puedan ser palpables sensorialmente son las que deberían ser concebidas como conocimiento. Como mencionaba el propio Hume, "sólo la experiencia -basada en las sensaciones- nos enseña la naturaleza y límites de causa y efecto, y nos permite inferir la existencia de un objeto de la de otro" (Hume 1992, p.191).

Al respecto, el autor sostiene y justifica el olvido de lo metafísico en la poca capacidad de este para ser ejecutado en la realidad, haciendo que sea visto como desconfiable en tanto no puede materializarse. Naturalmente, este tipo de percepciones tuvieron un efecto claro: el alejamiento sistemático de la religión.

Bajo la lógica de Hume, la religión tendría que ser vista con cierto grado de escepticismo en tanto alejaría al ser humano de las sensaciones empíricas, colocando su fe en un Dios que ni siquiera puede ver.

Sobre el particular, nos atrevemos a decir que no estamos de acuerdo con lo sostenido por el referido autor, toda vez que consideramos que la persona, por su propia naturaleza humana, tiene una inherente tendencia hacia lo espiritual; y sobre ello, no solo no estamos refiriendo al ámbito religioso, sino que consideramos todo aquello que sea capaz de llevar a una determinada persona a la trascendencia (cultura, música, contacto con la naturaleza, 
danza, etc.).

Aunque autores como Martí (2015), explican, adicionalmente, que el factor religioso adquiere otro grado de relevancia al determinar ciertos patrones morales para los individuos, los mismos que serán claves al momento de edificar las principales reglas morales dentro de una sociedad.

Así, la religión no solo es un fenómeno más en la vida de los individuos, sino que resulta ser un espacio donde cimenta sus propios principios morales y éticos, los cuales serán claves para la convivencia social.

Por tanto, prescindir de todo tipo de conocimiento o contacto más allá de lo palpable estaría llevando a obviar una esfera importantísima en la vida del ser humano, que se refiere a la esfera del sentido de su propia vida.

\subsection{Estructuralismo}

Finalmente, queremos hacer hincapié en una cuarta característica, surgida a mediados del siglo XX. Así, la corriente posmoderna comenzó a plantear que el ser humano realmente no debería ser entendido como el centro de la existencia. De esta forma, se comenzó a concebir la propia existencia del ser humano como parte de una estructura más grande y compleja, en la cual este era un mero partícipe pasivo. A esta corriente se le conoció como estructuralismo.

Esta teoría propone que las diversas interacciones realizadas por el individuo, realmente, están cimentadas en estructuras sociales, entendidas como la verdadera base de lo real, en tanto dejan al hombre como un ente dependiente de dicha estructura (Federación de Enseñanza de CCOO de Andalucía, 2011).

Al respecto, serán las estructuras sociales, y no el individuo, las determinarán el sentido de las relaciones sociales de este. Es, bajo dicha lógica, que Foucault (1968) estimó el fin del hombre, en tanto se le dejaba de percibir como el protagonista de su propia historia.

No obstante, el autor dio un paso más, proponiendo que el hombre no solo es un ente pasivo dentro del mundo que le rodea, sino incluso dentro del mundo de las ideas.

Así como existirían estructuras representadas en la realidad, también, según Foucault 
(2002), existirían corrientes de pensamiento que terminarían por condicionar el sentido de su vida, sin que este pueda mostrar mayor resistencia.

En ese sentido, Foucault entiende que la imposición de una razón universal un elemento constante de dominación y vigilancia, la cual sometería al hombre bajo su umbral, impidiéndole ejercer plenamente su rol activo.

Bajo esta óptica, la razón ya no liberaría al ser humano en su búsqueda de la verdad universal, sino que, por el contrario, lo estaría sometiendo, impidiéndole ejercer por su cuenta sus libertades individuales según su propia concepción personal.

Habiendo repasado brevemente las características más llamativas del pensamiento posmoderno, no debería sorprendernos que, en vista de lo mencionado, hoy muchos colectivos ciudadanos procuren una sobreexaltación de las libertades individuales, incluso en desmedro de otros derechos individuales.

De esta forma, aterrizando en el campo de la bioética y biojurídica, podemos apreciar cómo los debates en torno a casos como el aborto o la eutanasia parecen estar dirigidos reivindicar visiones individualistas de los derechos humanos, obviando todo tipo de consideración hacia los derechos de terceros y eliminando todo tipo de reflexión racional en torno al bien común, con el fin de orientar debidamente nuestras decisiones más allá de nosotros mismos.

Ello lo podemos ver, por ejemplo, en el tema del aborto, donde haciendo mención a las posibles afectaciones a la integridad de las mujeres se procura la eliminación sistemática de otros seres vivos. Una lógica similar ocurre respecto de la eutanasia, donde se pone en tela de juicio la dignidad humana por aplicación la supuesta libertad para decidir incluso sobre la propia vida.

Como mencionamos en las primeras líneas de la presente investigación, si bien sendos debates son motivos para investigaciones más complejas, creemos que las tendencias que se han venido produciendo a favor tanto del aborto como de la eutanasia u otros fenómenos análogos, responden a una inaplicación del uso de la razón, en tanto se estaría omitiendo el uso de una guía ética que permite reconocer mutuamente la dignidad del resto.

Del mismo modo, estas medidas serían fruto de un relativismo moral al cuestionar principios como la defensa de la vida que, se entiende, debería tener carácter de universal debido a su trascendencia; así como de un escepticismo sobre el conocimiento metafísico, en tanto 
conceptos, como la dignidad, no tendrían el mismo valor que las cuestiones materiales que sí podrían resultar visibles en la realidad.

Finalmente, también serían fruto de la aplicación de la lógica estructuralista, toda vez que exaltan la respuesta rebelde por parte de la autonomía del hombre para no sentirse oprimida bajo conceptos restrictivos como la razón.

\section{Algunas corrientes filosóficas o culturales postmodernas claves}

Creemos que lo mencionado en el anterior acápite, puede manifestarse en la aplicación de dos corrientes propias del pensamiento posmoderno, las cuales, hasta el día de hoy, tienen mucha vigencia: el utilitarismo y el neoliberalismo.

Sobre ello, consideramos a las mencionadas como claves en el desarrollo de muchos de los problemas bioéticos y biojurídicos.

\subsection{Utilitarismo}

Aplicando un orden cronológico, se pasará a hablar del utilitarismo como pensamiento y teoría de la justicia, detallando el origen de esta corriente y sus principales postulados.

\section{A. Origen}

Desde mediados de siglo XVIII, comenzó un serio cuestionamiento hacia la teoría iusnaturalista, la cual se vio cuestionada debido lo abstracto de sus planteamientos, lo cual podría conllevar a aplicaciones subjetivas ante la poca claridad de sus preceptos.

Bajo ese escenario, es que surge la idea la idea de establecer qué es lo justo en cada caso en base a cálculos concretos, y ya no en derechos "invisibles" o en términos vagos.

Al respecto, Bentham edificó como principal postulado del utilitarismo que este velara por la maximización de la felicidad, siendo que, en caso de controversias, se debería optar por la alternativa que garantice el máximo grado de bienestar a las partes, reduciendo todo tipo de dolor (Sandel, 2011).

De esta forma, mientras más utilidad, entendida como beneficio, se obtenga y menos dolor se produzca, más justa es una decisión. 
No obstante, debemos resaltar que, desde la misma concepción de la teoría de Bentham, pareciera destacarse cierta noción hedonista, al concebir al ser humana como un ente buscador de placeres, como si esta fuese la única aspiración que tuviera para poder desarrollarse plenamente.

Bajo esa lógica, las decisiones que cualquier persona tome, independientemente del ámbito, deberían estar orientadas por el beneficio que obtendría, omitiendo todo tipo de reflexión metafísica.

\section{B. Principales postulados}

Como adelantamos, el utilitarismo básicamente propone que la justicia se determina en base a la utilidad, entendida como beneficio o placer, que produce una determinada decisión.

Habría que destacar que, en principio, la teoría utilitarista tiene una intención loable, es decir, resulta evidente que todo el mundo sin excepción quiere maximizar la felicidad y disminuir el dolor.

No obstante, no debemos perder de vista que la mayor crítica hacia esta corriente está en que, indirectamente, le da a las mayorías la posibilidad de imponerse a las minorías (porque la felicidad de estos, al corresponder a una mayor cantidad de personas, siempre será mayor que el dolor producido a una minoría) y, por otro lado, parece plantear que, incluso principios fundamentales para la sociedad como los derechos humanos, puedan medirse matemáticamente, pudiendo ser restringidos de forma sistémica.

Considerando lo anterior, algunos califican, y con razón, al utilitarismo de Bentham como una dictadura de las mayorías sobre las minorías, quedando estas últimas a merced de los beneficios de sus contrapartes, inclusive si con ello se afectan sus derechos humanos.

Por ejemplo, si se hiciera algún referéndum para poder determinar si el aborto debería ser legalizado o no, habría el riesgo de que el $50.01 \%$ de los peruanos determine la suerte de otros seres vivos, colocando los derechos de los implicados a merced de unos votos contabilizados matemáticamente.

La aplicación de la lógica anterior solo conllevaría a un desconocimiento progresivo de la naturaleza de los derechos inherentes al ser humano, los cuales son inalienables con el fin de resguardar adecuadamente al individuo. En ese sentido, ¿puede una determinada medida 
que afecta a una población ser aprobada si cuenta con el respaldo de la mayoría de personas?, según Bentham sí, siempre y cuando ello produzca el mayor beneficio para la mayoría de personas.

No obstante, posturas como la mencionada también despertaron la crítica de muchos otros pensadores. En ese sentido, Rawls elabora una crítica contractualista al utilitarismo, señalando que su teoría irrumpe el estado de igualdad que debería consagrarse para el establecimiento de los fundamentos que deberían regir en una sociedad justa. Sobre el particular, uno de estos fundamentos, según el autor, consiste en que cada persona tenga la misma posibilidad de acceder a una gama de libertades básicas, en donde el Estado debería tener un rol activo, garantizando las condiciones mínimas de igualdad (Gargarella, 1999).

Ahora, si bien, posteriormente a Bentham, hubo intentos por tratar de humanizar al utilitarismo (por ejemplo, en la teoría del Mill), la esencia de la teoría se mantuvo, siendo que hasta el día de hoy puede verse reflejada, principalmente en controversias bioéticas.

A modo de ejemplo, resulta llamativo cómo muchas veces los casos de eutanasia son determinados en base a cálculos utilitaristas. Podrían existir casos donde se decida que una persona en estado vegetativo permanente ha dejado de ser "productiva", al no producir ningún tipo de beneficio ni propio ni para terceros, por lo que su vida puede ser prescindible, considerando los posibles gastos que traerían consigo mantenerlo con vida.

\subsection{Neoliberalismo}

La otra corriente surgida del pensamiento posmoderno y que se ha arraigado en la sociedad actual es neoliberalismo, el cual se ha erigido como un sistema principalmente económico, aunque sus postulados podrían replicarse para nuevos ámbitos, como el de la justicia y la bioética.

\section{A. Origen}

Como puede deducirse por el nombre, el origen de esta corriente nace del liberalismo clásico, que proponía la reivindicación de la esfera de libertades individuales de los individuos, la misma que debería ser cuidada y resguardada de todo tipo de intromisión, incluso del propio Estado.

Así, bajo esta óptica, el Estado no podría imponernos ningún modo de vida ni interferir en 
nuestra toma de decisiones. Todo lo contrario, debería brindar las condiciones para que sean los mismos individuos quienes puedan determinar sus proyectos de vida (Gallo, 1986).

Si bien el objetivo del liberalismo era resguardar la protección del individuo por encima del Estado, consideramos que dicha apreciación podría no resultar idónea. Las teorías liberales, en sí, proponen que no deberían existir intromisiones a la esfera de derechos de una persona, pero bajo esta lógica, habría que considerar qué tanta legitimidad tendría las normas básicas de convivencia.

Sin embargo, a pesar de sus cuestionamientos, el liberalismo recobró vigencia con el avance de las teorías utilitaristas, sobre las que ya hablamos en el acápite anterior.

Así, a diferencia de otras teorías liberales del siglo XX (como, por ejemplo, la planteada por Rawls), el neoliberalismo buscaba consagrarse como una teoría "auténticamente liberal", consagrando que el Estado no solo no debería decirnos cómo vivir, sino que ni siquiera estaría legitimado para intervenir de alguna forma en la vida de los ciudadanos, así sea en su beneficio.

Del mismo modo, se consagra el principio de neutralidad como la pauta de comportamiento del Estado. Bajo este principio, se debería impedir que el Estado realice políticas públicas que alteren la vida de la sociedad, incluso aquellas que busquen beneficiar a la gente más desfavorecida, aunque sobre esto hablaremos en el siguiente acápite.

\section{B. Principales postulados}

Según Nozick, un Estado intervencionista como el que, por ejemplo, proponía Rawls (el cual tenía la misión de proveer determinados bienes esenciales), impide que los ciudadanos sean completamente libres.

Únicamente, se podría admitir la participación activa del Estado si es que con esta se logra salvaguardar ciertas cuestiones esenciales (como la vida o la propiedad privada); sin embargo, no debería permitirse ni siquiera las intervenciones que busquen crear acciones afirmativas en beneficio de las poblaciones más vulnerables (Gargarella, 1999).

Al respecto, se consagran los denominados "derechos de no interferencia" (Gargarella, 1999), que proponen no solo que otros no restrinjan mis libertades básicas, sino que tampoco puedan ayudarme a proveerme de bienes, salvo acuerdo voluntario entre las partes 
(es decir, no como políticas públicas).

Como mencionamos anteriormente, y como también indica Sandel (2011), esta postura asumida por los neoliberales resulta cuestionable toda vez que impediría incluso que los Estados realicen acciones para compensar la desigualdad económica:

De esta forma, independientemente de los problemas sociales que pudieran existir (por ejemplo, falta de oportunidades, desigualdad económica, entre otras), según la postura de Nozick, estas deberían solucionarse por la misma acción de los individuos, y no por la intervención del Estado, el cual debe mantener su deber de neutralidad incluso en estos casos.

Posteriormente, ya entrado el Siglo XX, Hayek (1960) propone una nueva versión del liberalismo desde el capitalismo, en donde las principales actividades de la comunidad no necesariamente se determinaban por la mera libertad subjetiva de los individuos, sino que respondía al mercado.

Así mismo, Friedman sostenía que las políticas públicas del Estado no deberían colisionar con lo que el libre mercado determine (Sandel, 2011). Cabe mencionar, que este "mercado" será determinado por la propia interacción de los individuos bajo las leyes de la oferta y la demanda, sin ningún tipo de intervención externa. Así, se llegaría a la idea de que el mercado se regula solo.

Los autores referidos sostienen que, solo asegurando un rol la neutral por parte del Estado en la economía, se podrá garantizar una auténtica promoción de la libertad, dejando que los mismos ciudadanos determinen su suerte a través de las interacciones económicas básicas.

Sobre el particular, pareciera que la tesis neoliberal ha encontrado arraigo dentro de nuestros tiempos, en donde, en aras de la defensa de las libertades, se busca excluir todo tipo de rastro de imposiciones morales relacionadas a cómo deberían vivir su vida los ciudadanos.

Así, serán únicamente estos quienes, a través del mutuo consentimiento entre las partes, acordarán la ayuda hacia los menos beneficiarios. No obstante, lo anterior podría conllevar a una serie de situaciones donde se pongan en tela de juicio los derechos humanos. Como indica Sosa (2012), la conversión de esta teoría económica en una teoría del pensamiento ha consolidado un modelo único de desarrollo, en donde los costos y el 
nivel de desarrollo humano de los implicados pasa a un segundo nivel, si es que los comparamos con la idea de progreso que viene siendo impuesta por el mercado.

Relegar al Estado a un rol contemplativo (salvo se trate de la protección de la vida o la propiedad) sería menoscabar las funciones del que debería ser el principal garante de los derechos de los individuos.

Si el Estado no estuviera pendiente de la debida protección de los derechos individuales, estos estarían a merced de las leyes de la oferta y demanda, las cuales podrían consolidar escenarios de subordinación hacia determinados grupos sociales.

Así, el empoderamiento del mercado se muestra omiso ante muchas de las vulneraciones existentes en dicho sistema, consolidando la estructuración de relaciones asimétricas entre ciudadanos.

Consideramos que no hay ninguna garantía de que la teoría del libre mercado pueda remediar adecuadamente la situación de los sectores más necesitados.

Incluso las reglas del mercado no resultan enteramente neutrales como parece indicar el neoliberalismo. Ello, dado que habrá sectores más poderosos económicamente que, mediante la imposición de sus privilegios, buscarán favorecerse de forma prioritaria, pasando por encima de las necesidades de los demás.

Aterrizando dentro de los debates bioéticos contemporáneos, es observable cómo alrededor de temas como el aborto o la eutanasia, entre otros, se esconden también intereses económicos.

Bajo el pensamiento de Hayek o Friedman, no habría razones para impedir que el mercado también pueda determinar la viabilidad de estas medidas, toda vez que, al ser servicios "solicitados" (demanda) deberían permitirse que libremente alguien decida atenderlos (oferta) en caso estuviera en su disponibilidad y siempre que haya consentimiento mutuo para ello.

\section{Reflexiones finales: ¿Hacia dónde vamos?}

Un conocido refrán menciona que, para saber a dónde vamos, primero tenemos que saber de dónde venimos, lo tiene mucho de verdad. No obstante, colocando el referido dicho en 
sentido inverso, se podría determinar que conocer de dónde venimos también nos ayuda a saber hacia dónde no debemos ir.

Lo anterior, naturalmente podría aplicar para varios ámbitos y para varios escenarios. Uno de estos es el de la bioética y biojurídica.

Así, estas ramas del conocimiento se cimientan sobre ideas claras: la defensa de la vida y de los derechos humanos. De ese modo, para poder entender cómo deberían ser contempladas hoy en día, se debe retornar constantemente hacia dicho fin.

Las diversas tendencias ideológicas propias del pensamiento posmoderno, como las mencionadas en el presente artículo, son propias de escenarios concretos, que fueron campos de cultivo para que se expandan en la sociedad.

Como mencionamos, muchos de los debates en torno a temas como el aborto o la eutanasia han sido llevados por estas nuevas corrientes de pensamiento, promoviendo decisiones que afectan directamente los derechos de los involucrados.

En relación al aborto, podemos ver la influencia de estas corrientes dentro de la justificación con la que es legalizado. De este modo, se suele argumentar que, debido al estado embrionario, realmente no resulta tan grave acabar con su vida. Ello podría ser resultado de un examen utilitarista, donde se perciben supuestas ventajas que tendría la realización de un aborto en comparación con las aparentes cargas que conllevaría la maternidad. Del mismo modo, no hay que perder de vista la gran cantidad de dinero que mueven las industrias que se dedican a este tipo de operaciones. $Y$ es que, lamentablemente, como señalaba Sosa (2012), las pautas del mercado han hecho que se prioricen los caminos que conducirían al supuesto desarrollo económico, incluso si hay que consentir el aborto de otro ser vivo.

Con respecto de la eutanasia ocurre algo similar. Hoy en día muchas personas que están en un estado vegetativo son vistas como "poco útiles", es decir, no susceptibles de producir ningún tipo de beneficio dentro del sistema económico, siendo que no solo no pueden trabajar, sino que tampoco pueden adquirir bienes. Bajo esa premisa, sería entendible que se cree la noción de que sus vidas ya no merecerían ser vividas, lo cual, claramente, atentaría contra la dignidad de las referidas personas. Incluso, resulta llamativo que se suele emplear la expresión "muerte digna" como intento de justificar la negación de la propia dignidad de los referidos. 
Precisamente, debido a planteamientos como los mencionados, es que la bioética y biojurídica se consagran como bastiones para la debida defensa de la persona y su dignidad, independientemente de las circunstancias de cada caso concreto.

Si bien debería permitirse el debate académico entre distintas formas de entender un determinado tema, sobre todo en casos como los mencionados que, usualmente, resultan complejos, consideramos que la mejor manera de poder entender la labor de la bioética y biojurídica en dichos casos, es poder distanciarlas de corrientes que, contrariamente a sus fines, buscan desconocer el real valor del ser humano.

Hoy en día, los derechos humanos se quieren colocar en una balanza, con el fin de ser evaluados como cualquier otra mercancía. Ello no debería permitirse, en tanto la defensa de la dignidad de los seres humanos resulta incalculable, escapando de todo tipo de intento por compararla con otros bienes.

De esta forma, para saber hacia dónde debe ir la defensa de la dignidad humana se debe tener presente de dónde viene y los fines que defiende; pero ello conlleva a saber diferenciarla de tendencias posmodernas que han venido influenciando negativamente en la lucha por la justicia.

\section{Conclusiones}

Hoy en día, varios debates sobre temas controversiales, propios de la bioética y biojurídica, han venido siendo influenciados por una serie de corrientes propias del denominado pensamiento posmoderno. Las principales características de este tipo de pensamiento son la negación de la razón como instrumento guía, la relativización de la moral, el escepticismo hacia la metafísica y su visión estructuralista; al respecto, estas han terminado por consolidar un escenario donde la persona humana busca alejarse de las reflexiones internas, por considerarlas prescindibles, apegándose al plano más técnico y palpable, obviando toda reflexión moral sobre sus decisiones.

Estas características han terminado por consolidar un escenario donde la persona humana busca alejarse de las reflexiones internas, por considerarlas prescindibles, apegándose al plano más técnico y palpable, obviando toda reflexión moral sobre sus decisiones. 
Dicho pensamiento se ha venido concretando en dos teorías que han alcanzado mucho arraigo en el último siglo: el utilitarismo (que promueve la toma de decisiones a partir del beneficio para las mayorías) y el neoliberalismo (que promueve la imposición del mercado como pauta de las relaciones sociales).

Los debates sobre la bioética y biojurídica deben partir sobre la debida defensa de la persona y su dignidad, diferenciándola de otras teorías que han sido desarrolladas en el presente artículo.

\section{Recomendaciones}

Exhortar a que, en lo que respecta a los debates bioéticos y biojurídicos, se destaque el real fin de ambas ramas: la defensa de la dignidad y los derechos de la persona.

Reafirmar el compromiso de la bioética y biojurídica para no alterar sus propios fines por la influencia de corrientes posmodernas; si bien la confrontación de ideas es parte una sociedad democrática, ello no debería variar la esencia de ambas ramas del conocimiento.

Recordar que la dignidad y los derechos del hombre son bienes incalculables, que no deberían ser susceptibles de cálculos matemáticos de utilidad ni mucho menos estar a la merced del mercado.

\section{Referencias}

Aguirre, D. (2016). El escepticismo de San Agustín en Contra Los Académicos. Intus Legere, 10 (1), 37-53.

Blanco, P. (2005). "La razón en el cristianismo. Una reivindicación de Joseph Ratzinger". En Scripta Theologica. № 37 (2005/2), pp. 643-659.

De La Vega, M. (1991). "La filosofía política de Comte y su proyecto social". En Ideas y Valores, 40 (85), 71-90.

De Lora, P. (2006). Memoria y frontera. El desafío de los derechos humanos. Madrid: Alianza Editorial.

Gallo, E. (1986). "Notas sobre el liberalismo clásico". En Estudios Públicos. No 21 (1986). Obtenido de: https://bit.ly/32kTi1Q

Gargarella, R. (1999). Las teorías de la justicia después de Rawls. Un breve manual de filosofía 
política, Barcelona: Paidós.

Federación de Enseñanza de CCOO de Andalucía. (2011). "El Estructuralismo: Claude Levi Strauss". En Temas para la educación: Revista digital para profesionales de la enseñanza. №14 (2011), pp.1-19.

Fisichela, R. (2011). Posmodernidad y humanismo cristiano. Cuestiones Teológicas, 38 (89), pp.121133.

Foucault, M. (1968). Las Palabras y las cosas. Una arqueología de las ciencias humanas. Buenos Aires: Siglo XXI Editores.

Foucault, M. (2002). Vigilar y castigar. Nacimiento de la prisión. Buenos Aires: Siglo XXI Editores.

Hayek, F. (1960). Los fundamentos de la libertad. Madrid: Unión Editorial

Hume, D. (1992). Investigación sobre el conocimiento humano. Madrid, Alianza Editorial.

Juan Pablo II. (1998), Encíclica Fides et Ratio.

Lobato, A. (2000). La persona en Santo Tomás de Aquino. Obtenido en: https://bit.ly/3H83kSy

Martí, J. (2015). La religión ante la Ley. Manual de Derecho Eclesiástico. Madrid: Digital Reasons.

Reyes, M. (2013). La respuesta está en el viento. Estados Unidos. Palibrio.

Sandel, M. (2011). Justicia ¿Hacemos lo que debemos? Barcelona: DeBolsillo.

Sosa, S. (2012). Otro mundo es posible: crítica del pensamiento neoliberal y su visión universalista y lineal de las relaciones internacionales y el sistema mundial. En Revista mexicana de ciencias políticas y sociales, 57 (124), pp.55-86.

\section{Cómo citar este trabajo}

Santome Sánchez, A. A. (2021). ¿Hacia dónde vamos? El pensamiento postmoderno y su influencia en los conflictos o dilemas bioéticos y biojurídicos. Apuntes De Bioética, 4(2), 172-191. https://doi.org/10.35383/apuntes.v4i2.700

\section{Financiación}

El presente artículo no cuenta con financiación específica de agencias de financiamiento en los sectores público o privado para su desarrollo y/o publicación.

\section{Conflicto de interés}

Los autores del artículo declaran no tener ningún conflicto de intereses en su realización.

(c) Los autores. Este artículo es publicado por la Revista Apuntes de Bioética del Instituto de Bioética, Universidad Católica Santo Toribio de Mogrovejo.

(1) (2) Este es un artículo de acceso abierto, distribuido bajo los términos de la Licencia Creative EY NC SA Commons Atribución-NoComercial-CompartirIgual 4.0 Internacional (CC BY-NC-SA 4.0), que permite el uso no comercial, distribución y reproducción en cualquier medio, siempre que la obra original sea debidamente citada. 